http://journal.unj.ac.id/unj/index.php/jpud

Volume 12 Edisi 2 November 2018

JURNAL PENDIDIKAN USIA DINI

DOI: https://doi.org/10.21009/JPUD.122

DOI: https://doi.org/10.21009/JPUD.122.09

\title{
PENGEMBANGAN MEDIA SLIDING BOOK UNTUK PENGENALAN SAINS KEHIDUPAN (LIFE SCIENCE) KELAUTAN UNTUK ANAK USIA DINI
}

\author{
Muktia Pramitasari ${ }^{1}$, Elindra Yetti $^{2}$, Hapidin $^{3}$ \\ Program Studi Pendidikan Anak Usia Dini, Universitas Negeri Jakarta \\ E-mail: muktiapramitasari_s2@mahasiswa.unj.ac.id ${ }^{1}$, elindrayetti@unj.ac.id ${ }^{2}$, \\ hapidin@unj.ac.id ${ }^{3}$
}

\begin{abstract}
ABSTRAK
This study aims to develop sliding book as medium to introduction of marine life science in early childhood. The research method used is research \& development with ADDIE model. The data collection technique used based on the result of expert vaidation and effectiveness test through quasi experiment with data analysis of paired t-test statistic. The study involved childhren age 6-7 years in Tangerang Selatan distric. The results of research and product development shows: 1) the sliding book medium design is feasible to introduce the marine life science, 2) the effectiveness of medium is shown by the result of pre-test \& post-test of childhren obtain by the t-value, and sig. 2 tailed $<$ $0.05,3)$ the validity of mdium indicated by the test of life science material expert recommendation of this research is the effort to develop marine literacy media for early childhood, so it will be rich in marine insight, formed a strong mindset and marine spirit.
\end{abstract}

Keywords: Early Chilhood, , Life science, Marine, Sliding Book

Penelitian ini bertujuan untuk mengembangkan media sliding book untuk pengenalan sains kehidupan kelautan untuk anak usia dini. Penelitian dilakukan dengan metode penelitian research \& developmet/R\&D. Data dikumpulkan melalui analisis kebutuhan (studi literatur, analisis komparatif, wawancara \& observasi), angket untuk pakar, pre test dan post test untuk anak. Analisa data kualitatif dilakukan berdasar hasil wawancara dan observasi sedangkan kuantitatif dengan uji t- berpasangan. Hasil penelitian menunjukkan bahwa perancangan media sliding book layak dan efektif untuk mengenalkan sains kehidupan kelautan. Rekomendasi penelitian ini yaitu upaya mengembangkan media literasi tentang kelautan untuk anak usia dini, sehingga kelak akan kaya akan wawasan kelautan, terbentuk pola pikir dan jiwa kelautan yang kuat.

Kata Kunci: Anak Usia Dini, Sains Kehidupan, Kelautan, Sliding Book

\section{PENDAHULUAN}

Anak usia dini mengembangkan pemahaman mendasar tentang konsep sains selama tahun-tahun awal sekolah (Guo, Piasta, \& Bowles, 2015). Perkembangan konsep dan keterampilan sejak masa bayi hingga masa kanak-kanak awal akan dijadikan dasar dan strategi bagi guru yang diperlukan dalam pembelajaran inquiri dalam sains (Lind, 1998). Salah satu konten sains yang penting sebagai sarana mengembangkan aspek-aspek perkembangan anak usia dini adalah sains kehidupan. 
Indonesia adalah negara maritim yang terdiri atas ribuan pulau yang memiliki keunggulan kompetitif (Fuad \& Musa, 2017), namun pengenalan tentang kehidupan kelautan masih sangat minim dilakukan khususnya pada anak usia dini. Hal tersebut dapat menjadi salah satu penyebab pola pikir kelautan yang semakin terkikis. Media dalam hal ini dapat menjadi sarana untuk menjadi solusi permasalahan tersebut terutama media literasi. Cerita bergambar merupakan media penyampaian pesan yang kuat untuk anak usia dini dengan kelebihan gambar yang ada dalam cerita merupakan sesuatu yang membuat anak menjadi tertarik serta dapat membantu anak memahami isi cerita walaupun belum lancar kemampuan membacanya, selain itu konsep atau suasana yang bersifat abstrak dan tidak dapat di jelaskan dengan katakata namun dapat dijelaskan melalui ilustrasi/gambar (Effendy et al., 2017). Media buku cerita bergambar dapat menyampaikan konsep-konsep atau pengetahuan tentang dunia nyata di sekitar anak-anak (Gonen \& Guler, 2011). Melalui buku cerita bergambar juga dapat meningkatkan konsep pengetahuan tentang lingkungan pada anak usia dini (C. Hsiao \& Shih, 2015).

Berdasarkan analisis kebutuhan diketahui bahwa permasalahan saat ini terkait literasi adalah masih minimnya media literasi bertema kelautan yang menarik dan memiliki konten yang tepat bagi anak usia dini. Berdasarkan pengamatan dan survey terhadap media literasi kelautan yang tersedia di lapangan diketahui pula bahwa media literasi masih jarang, belum variatif dan konten di dalamnya belum spesifik membahas tentang kehidupan di laut. Kurangnya media tersebut, didukung dari hasil dari studi komparatif tentang bukubuku kelautan adalah belum ada yang mengembangkan buku cerita anak usia dini berbentuk sliding book yang berisi materi tentang kelautan khusus pengenalan sains kehidupan (life science) pada ekosistem terumbu karang, ekosistem lamun dan ekosistem pohon bakau.

Hal tersebut diperkuat lagi dengan pernyataan dari Lembaga Ilmu Pengetahuan Indonesia (LIPI) bahwa materi pengajaran tentang kelautan masih terbatas dan masih berorientasi pada wilayah darat dan materi pendidikan tentang kelautan harus dapat dijangkau anak sedini mungkin (LIPI, 2016).

Berkaitan dengan hal tersebut, akan dikembangkan media untuk anak yang mendukung pembelajaran sains khususnya tentang sains kehidupan kelautan. Pengembangan media tersebut yaitu media literasi sains berbentuk sliding book (inovasi buku cerita bergambar) yang menarik dan sesuai untuk anak usia dini. Pengembangan media sliding book dilakukan dengan tujuan sebagai alternatif untuk mengenalkan sains kehidupan kelautan. 
Pengembangan Media Sliding Book...

Muktia, Elindra, \& Hapidin

\section{KAJIAN TEORITIK}

\section{Pengenalan}

Pengenalan menjadi salah satu bagian dari kategori proses kognitif "mengingat". Proses mengingat terdiri dari aspek-aspek: 1) mengenali yaitu mengambil pengetahuan yang diperlukan yang berasal dari memori atau ingatan jangka panjang kemudian dibandingkan dengan informasi baru yang diterima; 2) mengingat kembali yaitu proses mengambil pengetahuan yang diperlukan dari memori jangka panjang dan membawa informasi tersebut untuk diproses di dalam memori kerja (Anderson, L. W. \& Krathwohl, 2017).

\section{Sains Kehidupan (Life Science) Kelautan}

Pengenalan tersebut akan dilakukan pada bidang sains kehidupan. Life science is the study of living things-plants and animals. It helps to explain how living things relate to one another and to their surroundings (Brierer \& Lien, 1981). Sains kehidupan adalah studi tentang makhluk hidup yaitu tumbuhan dan hewan. Hal ini membantu untuk menjelaskan bagaimana makhluk hidup berhubungan satu sama lain dan sekitarnya.

Konten/isi dari materi yang dapat diperkenalkan dan diajarkan untuk anak usia dini sampai kelas SD awal adalah: 1) karakteristik organisme (ciri-ciri makhluk hidup); 2) Siklus hidup organisme (proses kehidupan makhluk hidup); 3) organisme dan lingkungannya (lingkungan tempat tinggal makhluk hidup) (Charlesworth \& Lind, 2010).

Secara garis besar, ekosistem perairan laut dapat dibagi menjadi dua yaitu ekosistem pesisir dan ekosistem laut (Puspitaningsih, 2012). Penelitian ini akan membatasi pokok bahsan pada wilayah ekosistem pesisir pada wilayah ekosistem terumbu karang, ekosistem lamun, dan ekosistem pohon bakau. Berdasarkan beberapa teori disimpulkan sains kehidupan kelautan adalah pengetahuan mengenai fakta-fakta yang berhubungan dengan kehidupan organisme ekosistem pesisir yang meliputi ciri-ciri makhluk hidup di sekitar pesisir, proses kehidupan makhluk hidup di sekitar pesisir, dan lingkungan tempat tinggal makhluk hidup di sekitar pesisir.

\section{Media Sliding Book}

Menurut Arsyad pengertian media dalam proses pembelajaran diartikan sebagai alat-alat grafis, fotografis, atau elektronis untuk menangkap, memproses, dan menyusun kembali informasi visual maupun verbal (Arsyad, 2017). Secara implisit pernyataan tersebut menjelaskan bahwa media merupakan sarana prasarana yang berguna untuk membantu menerima dan mengolah informasi. 
Berkaitan dengan media pembelajaran dan pendidikan anak usia dini, Latif mengemukakan bahwa media adalah segala sesuatu yang dapat dijadikan alat dan bahan untuk bermain yang mampu membuat anak usia dini mampu memeroleh konsep pemahaman yang baru dan dalam istilah sering disebut dengan alat permainan edukatif (APE) (Latif, Zukhairina, Zubaidah, \& Afandi, 2013). Sebagai seorang guru/praktisi pendidikan khususnya guru anak usia dini, dituntut memiliki kreativitas untuk selalu menghadirkan media dalam setiap pembelajarannya karena anak usia dini berada dalam tahap berpikir secara konkret untuk menerima sebuah pemahaman.

Kozminsky dan Sadon dalam penelitiannya mengemukakan bahwa media cetak khususnya buku cetak memiliki peran dalam meningkatkan kemampuan literasi anak usia dini seperti penambahan jumlah kosa kata, pemahaman alur/plot, kesadaran fonologi serta mendukung kesiapan membaca dan menulis anak untuk memasuki jenjang sekolah lebih lanjut (Kozminsky \& Asher-sadon, 2013). Hal ini dapat dipahami bahwa media berbasis cetak berperan dalam meningkatkan kemampuan anak dalam literasi dan kesiapan sekolah.

Salah satu contoh bentuk media cetak untuk anak usia dini yaitu buku cerita bergambar. Buku cerita bergambar juga dapat menyampaikan informasi tentang suatu objek menjadi lebih jelas, apabila terdapat sebuah teks/tulisan tanpa gambar memungkinkan terjadinya imajinasi dengan interpretasi/pemahaman visual yang berbeda sesuai dengan intelegensi dan latar belakang pembaca yang berbeda-beda pula, namun dengan kolaborasi tulisan dan gambar perbedaan interpretasi/pemahaman tersebut dapat dibatasi dan menghasilkan penerimaan informasi yang sama dari sebuah cerita (Effendy et al., 2017). Pada intinya media buku cerita bergambar dapat menyamakan persepsi pembaca terhadap sebuah pesan/informasi yang terdapat pada cerita.

Selanjutnya Nurgiyantoro menyajikan hal-hal yang penting diperhatikan dalam perancangan buku bergambar, diantaranya adalah: (1) posisi dan format gambar; (2) bahasa buku bergambar; dan (3) isi buku bergambar (Nurgiyantoro, 2016). Ketiga hal tersebut dijadikan sebagai rujukan dalam pengembangan media sliding book.

Penelitian ini akan menyusun dan mengembangkan buku cerita bergambar bertema sains kehidupan kelautan untuk anak usia 6-7 tahun dalam rangka pengenalan tentang kehidupan makhluk hidup laut. Kemudian media buku cerita bergambar ini diinovasi dengan menggunakan teknik sliding (geser) sebagai alat bantu penambah daya tarik, semangat, dan motivasi belajar dengan tujuan materi yang disampaikan menjadi mudah pahami, 
Pengembangan Media Sliding Book...

Muktia, Elindra, \& Hapidin

lebih terkesan dan tersimpan lama di dalam memori sehingga disebut sebagai media sliding book.

\section{METODE PENELITIAN}

Media sliding book merupakan hasil dari penelitian dan pengembangan (Research and Development) dengan menggunakan model ADDIE (Analysis, Design, Development, Implementation \& Evaluation) (Branch, 2008). Penelitian dan pengembangan adalah sebuah metode penelitian yang mengkolaborasikan metode penelitian kuantitatif dan kualitatif dan dikemas dalam tahapan-tahapan tertentu dalam rangka uji efektivitas sebuah produk yang dikembangkan/diinovasi maupun produk baru/original.

Penelitian dilakukan di salah satu kota yang terletak di Provinsi Banten yaitu kota Tangerang Selatan. Subjek penelitian ini adalah anak usia 6-7 tahun yang berada di kota Tangerang Selatan. Penelitian ini melakukan analisis data kualitatif dan kuantitatif tentang pengenalan sains kehidupan (life science) kelautan. Analisis data kualitatif diperoleh melalui data hasil analisis kebutuhan (studi literatur, studi komparatif, wawancara \& observasi) sedangkan data kuantitaif yang diperoleh melalui hasil tes yang dilakukan sebelum (pre test) dan sesudah penggunaan media sliding book (post test). Kemudian nilai tesnya dianalisa melalui uji $\mathrm{t}$ berpasangan.

\section{HASIL DAN PEMBAHASAN}

\section{Hasil}

Desain media yang dikembangkan adalah berupa media sliding book berjudul "Petualangan si Piyu" untuk pengenalan sains kehidupan (life science) kelautan. Media sliding book merupakan hasil dari modifikasi buku cerita bergambar dengan menggunakan teknik sliding (geser). Tujuannya untuk menambah interaksi dan daya tarik anak ketika menggunakan media tersebut. Media ini juga memiliki tema unik yaitu sains kehidupan kelautan yang dikemas dengan cerita petualangan sederhana sesuai untuk anak usia 6-7 tahun. Media ini dikembangkan berdasarkan proses sebagai berikut:

\section{Analisis kebutuhan}

Analisis kebutuhan salah satunya dilakukan melalui observasi anak usia 6-7 tahun terhadap pengenalan mereka pada life science kelautan khusus pada ekosistem terumbu karang, lamun dan pohon bakau. Hasil observasi menunjukkan wawasan pengenalan anak dibawah $7 \%$ terhadap tiga ekosistem yang menjadi pokok bahasan yaitu ekosistem terumbu karang, ekosistem lamun dan ekosistem pohon bakau. Hasil wawancara menunjukkan minimnya stimulasi dari lingkungan keluarga, sekolah dan masyarakat terhadap pengenalan sains kehidupan kelautan. Hasil analisis komparatif 
terhadap buku bertema kelautan menunjukkan bahwa belum ada buku cerita bergambar tentang sains kehidupan kelautan khususnya tentang ekosistem terumbu karang, lamun dan pohon bakau. Studi literatur terhadap beberapa artikel juga menunjukkan bahwa belum ada penelitian terdahulu yang mengembangkan media sliding book untuk pengenalan sains kehidupan kelautan.

\section{Draft final media sliding book.}

Model ini merupakan hasil akhir dari pengembangan model dan telah melalui uji lima orang pakar/ahli, uji coba kelompok kecil terhadap 7 anak dan uji coba kelompok besar terhadap 25 anak di Kota Tangerang Selatan. Berikut bagan draft final media sliding book:

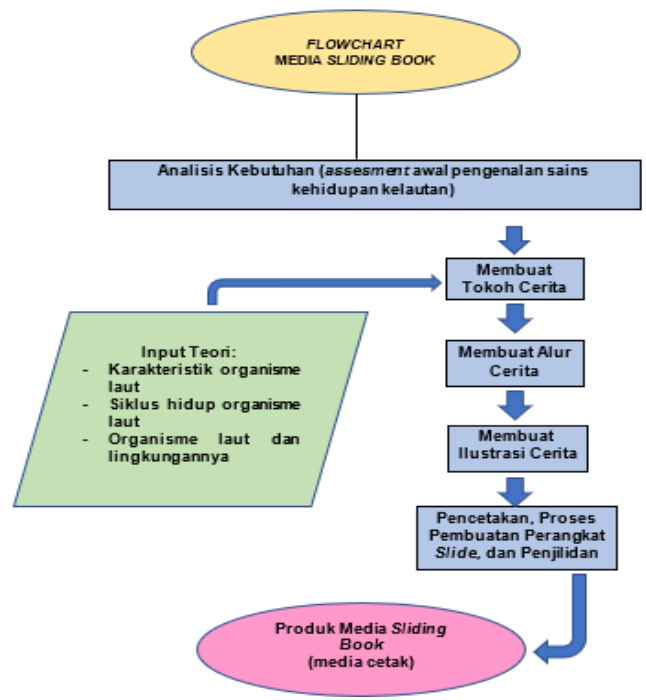

Gambar 1. Draft Final Media Sliding Book untuk Pengenalan Sains Kehidupan Kelautan 3. Uji Kelayakan

Berikut hasil uji kelayakan media sliding book yang diperoleh dari angket yang diberikan pada pakar/ahli:

Tabel 1. Hasil Uji Kelayakan Model

\begin{tabular}{|c|c|c|c|}
\hline No. & Pakar/Ahli & $\%$ & Kriteria \\
\hline 1. & PAUD & $100 \%$ & $\begin{array}{c}\text { Sangat } \\
\text { layak }\end{array}$ \\
\hline 2. & Bahasa & $78,6 \%$ & $\begin{array}{l}\text { Sangat } \\
\text { Layak }\end{array}$ \\
\hline 3. & Media & $95 \%$ & $\begin{array}{l}\text { Sangat } \\
\text { Layak }\end{array}$ \\
\hline $\begin{array}{l}4 . \\
5 .\end{array}$ & $\begin{array}{c}\text { Life Science } \\
\text { Kelautan }\end{array}$ & $\begin{array}{l}75 \% \\
75 \%\end{array}$ & $\begin{array}{l}\text { Layak } \\
\text { Layak }\end{array}$ \\
\hline
\end{tabular}

\section{Uji Efektivitas}

Uji efektivitas dilakukan dengan metode penelitian quasi eksperimen melalui pre test dan post test serta analisis menggunakan uji-t berpasangan. Nilai hasil perhitungan paired samples test dengan SPSS di peroleh hasil nilai Sig.(2-tailed) sebesar 0.000 , sehingga nilai $0.000<0.05$ maka data tersebut menunjukkan bahwa terdapat perbedaan dari sebelum dan sesudah penggunaan media sliding book untuk pengenalan sains kehidupan kelautan.

\section{Pembahasan}

Media secara garis besar terdiri dari manusia, materi, atau kejadian yang membangun kondisi siswa mampu memperoleh pengetahuan, keterampilan dan sikap (Effendy et al., 2017). Hadirnya media berperan vital bagi siswa dan guru untuk meningkatkan proses pembelajaran, meningkatkan partisipasi aktif dan berbagai kemampuan siswa (Manjale \& Abel, 2017). Penelitian ini menghasilkan sebuah produk "Media Sliding Book Untuk Pengenalan Sains 
Pengembangan Media Sliding Book...

Muktia, Elindra, \& Hapidin

Kehidupan (Life Science) Kelautan Anak Usia 6-7 Tahun." Media sliding book ini merupakan jenis media cetak berbentuk buku cerita bergambar yang dapat menyampaikan pesan atau informasi yaitu tentang sains kehidupan kelautan khususnya pada ekosistem terumbu karang, ekosistem lamun dan ekosisten pohon bakau. Hal ini terbukti melalui peningkatan dari skor pre-test ke post-test berikut:

Tabel 2. Hasil Pre-test dan Post-Test

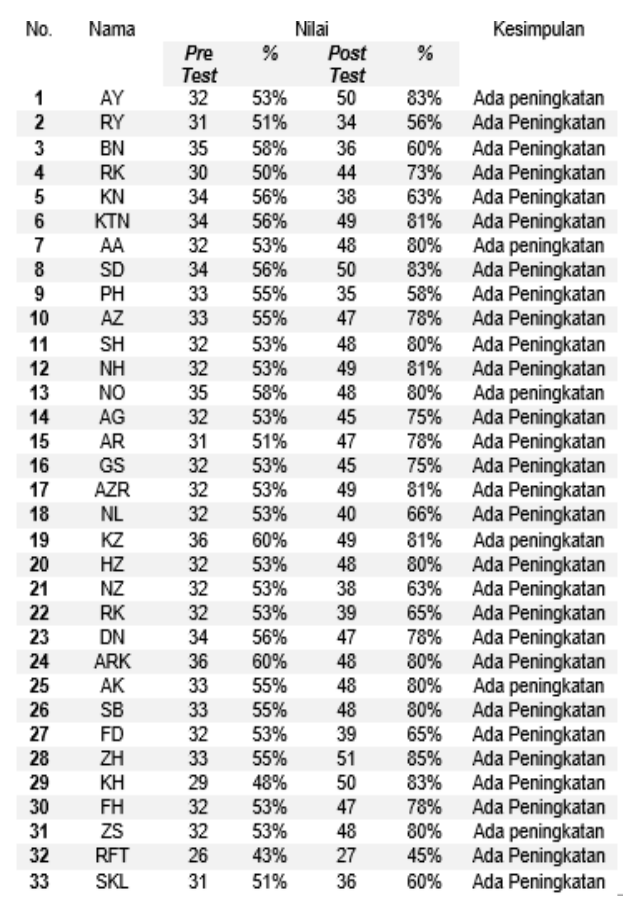

Buku bergambar dapat pula mempengaruhi anak usia dini dalam mempelajari fakta-fakta biologi pada hewan (Ganea, Ma, \& DeLoache, 2011). Berdasarkan hasil uji coba diperoleh fakta bahwa setelah membaca dengan menggunakan media sliding book anak-anak dapat menerima informasi dari konten yang disajikan yaitu mengetahui tentang kehidupan yang ada pada ekosistem pesisir khususnya pada ekosistem terumbu karang, ekosistem lamun dan ekosistem pohon bakau. Anak-anak mengetahui jika terumbu karang adalah jenis hewan, lamun berbeda dengan rumput laut, penyu dan kurakura adalah dua hewan yang berbeda baik dari segi fisik maupun tempat hidupnya, serta sangat antusias mengetahui fakta bahwa ikan dugong/duyung bukan berwujud seperti putri duyung seperti pada filmfilm yang pernah dilihat, tetapi merupakan jenis ikan yang bentuk fisiknya berbeda sekali dengan putri duyung, sehingga dengan mengenali, anak-anak dapat menjaga dan melestarikan biota-biota laut. Hal tersebut sejalan dengan pernyataan Gonen dan Guler dalam penelitiannya bahwa media buku cerita bergambar dapat menyampaikan konsep-konsep atau pengetahuan tentang dunia nyata di sekitar anak-anak (Gonen \& Guler, 2011).

Buku cerita bergambar "Petualangan si Piyu" mengandung pesan melalui ilustrasi dan teks yang tertulis. Rothlein dan Meinbach dalam Adipta \& Hasanah mengemukakan bahwa unsur cerita dan gambar sama-sama memiliki peran kuat dalam penyampaian pesan (Adipta, \& Hasanah, 2016). Dalam hal ini, unsur cerita dan gambar samasama memiliki peran kuat dalam penyampaian pesan, sehingga keterlibatan ilustrator untuk menciptakan ilustrasi untuk anak usia dini merupakan hal yang utama. Selain itu, keterlibatan pihak 
percetakan yang dapat mengeksekusi media ini sesuai yang peneliti rancang yaitu teknik sliding juga merupakan faktor yang sangat mendukung proses pengembangan media ini.

Melalui buku cerita bergambar anak-anak menjadi lebih peduli terhadap lingkungan(C.-Y. Hsiao \& Chang, 2015). Setelah membaca dan mengenali tentang kehidupan laut melalui media sliding book "Petualangan si Piyu", kemudian anak-anak diarahkan dan distimulasi agar kedepannya peduli terhadap kehidupan kelautan dengan diwujudkan melalui tindakantindakan yang positif dalam menjaga dan melestarikan lingkungan kelautan.

Media cetak memiliki peran juga dalam meningkatkan kemampuan literasi anak usia dini seperti penambahan jumlah kosa kata, pemahaman alur/plot, kesadaran fonologi serta mendukung kesiapan membaca dan menulis anak untuk memasuki jenjang sekolah lebih lanjut (Kozminsky \& Asher-sadon, 2013). Media sliding book selain memperkaya referensi tentang kelautan juga dapat menstimulasi perkembangan literasi anak usia dini. Hal ini dapat terjadi karena sliding book tersebut akan menjadi sarana menstimulasi anak agar terbiasa untuk cinta buku dan cinta membaca sejak dini.

Heinsbergen juga mengemukakan bahwa buku bergambar dapat dipakai untuk memperkenalkan tema yang baru maupun mengulas kembali tema sebelumnya serta dapat menstimulasi kemampuan literasi anak seperti membaca dan menulis (Heinsbergen, 2013). Hal-hal tersebut dapat dijadikan dasar bahwa media sliding book sebagai berbasis cetak memiliki dampak lain yaitu meningkatkan kemampuan anak dalam literasi dan kesiapan sekolah. Secara tidak sadar dan dengan cara yang menyenangkan anak akan menyerap berbagai kosa kata yang disajikan sehingga perbendaharaan kata bertambah. Hal ini berpengaruh bagi perkembangan bahasa anak dan kemampuan literasinya.

Hal lain yang ditemukan saat penelitian adalah pada saat uji coba kelompok kecil, terdapat anak berusia 7 tahun yang belum lancar membaca, namun ilustrasi yang ada pada media sliding book dapat membantu dalam memahami isi cerita. Effendy mengemukakan bahwa cerita bergambar merupakan media penyampaian pesan yang kuat untuk anak usia dini dengan kelebihan gambar yang ada dalam cerita merupakan sesuatu yang membuat anak menjadi tertarik serta dapat membantu anak memahami isi cerita walaupun belum lancar kemampuan membacanya, selain itu konsep atau suasana yang bersifat abstrak dan tidak dapat di jelaskan dengan katakata namun dapat dijelaskan melalui ilustrasi/gambar (Effendy et al., 2017). 
Pengembangan Media Sliding Book...

Muktia, Elindra, \& Hapidin

\section{KESIMPULAN DAN SARAN}

Sebagai negara yang memiliki wilayah laut yang luas seharusnya berbanding lurus dengan pengetahuan, pola pikir dan jiwa masyarakatnya tentang kelautan. Namun hal tersebut tidak sejalan dengan kenyataannya. Pengembangan media sliding book hadir sebagai salah satu solusi untuk menstimulasi pengetahuan, pola pikir, dan jiwa generasi bangsa sejak dini sehingga di masa depan anakanak lebih peka terhadap wilayah dan keanekaragaman hayati laut Indonesia serta menjadi lebih kreatif untuk menjaga, melestarikan dan mengembangkan kekayaan laut dari berbagai bidang.

Pengembangan-pengembangan media dalam bidang kelautan untuk anak usia dini agar terus digalakkan sehingga menjadi lebih variatif dalam rangka melestarikan dan memajukan potensi kelautan Indonesia.

\section{DAFTAR PUSTAKA}

Adipta, H., Hasanah, M., Dasar, P., \& Malang, P. N. (2016). Pemanfaatan Buku Cerita Bergambar, 989-992

Anderson, L. W., \& Krathwohl, D. R. (Ed. . (2017). Kerangka Landasan untuk Pembelajaran, Pengajaran, dan Asesmen. Yogyakarta: Pustaka Pelajar.

Arsyad, A. (2017). Media Pembelajaran. Branch, R. M. (2008). Instructional Design: The ADDIE Approach. Evolution.

Brierer, L. M., \& Lien, V. F. (1981).
Heath Life Science. Toronto: D.C. Heath and Company.

Charlesworth, R., \& Lind, K. K. (2010). Math \& Science for Young Children (6th ed.).

Effendy, Y., Bangsa, P. G., Sn, S., Sn, M., Yudani, H. D., Studi, P., ... Petra, U. K. (2017). Perancangan Buku Cerita Bergambar dan Gedunai untuk Anak Usia 4-6 tahun, 56-58.

Fuad, M. A. Z., \& Musa, M. (2017). Pengenalan Bidang Kemartiman Sejak Dini Melalui Pembelajaran Tematik Kelautan Pada Siswa Taman Kanak-kanak. Jurnal Pendidikan Geografi, 2, 93-104.

Ganea, P. A., Ma, L., \& DeLoache, J. S. (2011). Young children's learning and transfer of biological information from picture books to real animals. Child Development, 82(5), 1421-1433. https://doi.org/10.1111/j.14678624.2011.01612.x

Gonen, M., \& Guler, T. (2011). The environment and its place in children's picture story books. Procedia - Social and Behavioral Sciences, 15, 3633-3639. https://doi.org/10.1016/j.sbspro.20 11.04.347

Guo, Y., Piasta, S. B., \& Bowles, R. P. (2015). Exploring Preschool Children , s Science Content Knowledge Exploring Preschool Children ', s Science Content Knowledge, 9289(November). https://doi.org/10.1080/10409289.2 015.968240

Heinsbergen, N. A. (2013). The Positive Effects of Picture Books Providing Acceptance of Diversity in Social Studies and Increased Literacy in 
Early Childhood Education, 1-89.

Hsiao, C.-Y., \& Chang, Y.-M. (2015). A Study of the Use of Picture Books by Preschool Educators in Outlying Islands of Taiwan. International Education Studies, 9(1), 1. https://doi.org/10.5539/ies.v9n1p1

Hsiao, C., \& Shih, P. (2015). The Impact of Using Picture Books with Preschool Students in Taiwan on the Teaching of Environmental Concepts, 8(3), 14-23. https://doi.org/10.5539/ies.v8n3p1 4

Kozminsky, E., \& Asher-sadon, R. (2013). Media Type Influences Preschooler, s Literacy Development: E-book versus Printed Book Reading, 9, 231-245.

Latif, M., Zukhairina, Zubaidah, R., \& Afandi, M. (2013). Orientasi Baru Pendidikan Anak Usia Dini (Teori dan Aplikasi). Jakarta: Kencana Prenada Media Group.

Lind, K. K. (1998). Science in Early Childhood: Developing and Acquring Fundamental Concepts and Skills. Retrieved from ERIC (ED418777), 85.

LIPI. (2016). Materi Kelautan Terbatas. Retrieved from http://lipi.go.id/lipimedia/materikelautan-terbatas/16606

Manjale, N. B., \& Abel, C. (2017). Significance and adequacy of instructional media as perceived by primary school pupils and teachers in, 4(6), 151-157.

Nurgiyantoro, B. (2016). Sastra Anak (Pengantar Pemahaman Dunia anak). Yogyakarta: Gajah Mada University Press. 